\title{
Carotid Baroreflex Stimulation in Rats: A Novel Approach to Investigate resistant Hypertension and Immunity Responses
}

\author{
Domingos-Souza $\mathrm{G}^{1^{*}}$ and Munhoz $\mathrm{FC}^{2}$ \\ ${ }^{1}$ Department of Biomedical Sciences, University of Missouri, USA \\ ${ }^{2}$ Antonio Carlos President Institute, Brazil
}

Submission: September 14, 2017; Published: September 22, 2017

*Corresponding author: Domingos-Souza Gean, Department of Biomedical Sciences, Department of Medical Pharmacology and Physiology, Dalton Cardiovascular Research Center, University of Missouri 134 Research Park Drive, Columbia, MO, 65211, USA, Tel: +1 352 815 6797;

E-mail: geandomingosusp@gmail.com

Abstract

Litte is known about correlation of cardiovascular and inflammatory reflex. Electric activation of the carotid sinus (CS), also known as baroreflex activation therapy (BAT), have been used as an effective technology for controlling AP in patients with resistant hypertension. Up to date, therapeutic efficacy of BAT has been evaluated mostly in humans and canine model. The lack of an appropriate animal model can be a limiting factor to understandingdetails of mechanisms involved with cardiovascular system and immune responses.Recent studies in awake rats have clearly demonstrated that BAT evokes hemodynamic and immunological responses; however, its mechanism is not known. Thus, further studies utilizing this animal model may offer an important tool to clarify the mechanisms involved in the responses evoked by recruitment of autonomic nervous system and immune system mediated by the cardiovascular and inflammatory reflex.

Keywords: Baroreflex, Arterial Pressure, Resistant Hypertension, Electrical Stimulation, Inflammatory Reflex.

Abbreviations: CS: Carotid Sinus; BAT: Baroreflex Activation Therapy; AP: Arterial Pressure; CNS: Central Nervous System; NTS: Nucleus of the Solitary Tract; SHR: Spontaneous Hypertensive Rat; LPS: lipopolysaccharide

\section{Introduction}

\section{Baroreflex Mechanism}

Arterial baroreceptor reflex system is one of the most efficient and accurate mechanisms for controlling the arterial pressure (AP) and autonomic nervous system activity [1]. Variations in AP lead to distend arteries, stretching of carotid and aortic baroreceptors. These responses generate action potentials that are conveyed to medullary brainstem nuclei via the glossopharyngeal and vagus nerves. Along these nerves, these signals are projected directly into the central nervous system (CNS) to contact with neurons within the nucleus of the solitary tract (NTS) in the brainstem. After these signals arrive in the brainstem, the autonomic nervous system (via efferent parasympathetic and sympathetic nerves) is recruited to compensate the change in AP. Thus, the baroreflex is an important short-term regulatory system for the control of AP and this reflex mechanism is maintained in a narrow range of oscillation [2,3]. Damage in afferents or efferent baroreceptors is known to result in baroreflex and autonomic failure [4].

\section{Electrical Stimulation of Peripheral Nerves}

Several studies have been conducted to assess the effects of peripheral nerve stimulation as a treatment for diverse health conditions, in particular for those that no other therapy is available or conventional treatments are not entirely functional. This treatment is based on electrical stimulation of peripheral nerves that rely on the generation of action potentials in response to the flow of electrical current [5]. The stimulation of vagus nerve has been widely applied for use in depression [6], migraine [7], heart failure [8], morbid obesity [9], and inflammation [10] among others [11].

\section{Baroreflex Activation Therapy (Bat) and Resistant Hy- pertension}

Resistant hypertension is defined as AP that remains above established limits despite the concurrent use of three different antihypertensive agents of different classes, one of which should be a diuretic [12].Given the limitation of pharmacological thera- 
py for hypertension treatment in the past $[13,14]$, this electrical therapeutic approach was proposed in the early 60 s. However, it was posteriorly disused due to technology and manufacturing limitations. In attempts to controlling AP in patients with resistant hypertension, BAT (an implantable device resembling a cardiac pacemaker) have currently been usedin the management of resistant hypertension and heart failure [15-18].

Although electrical stimulation of the CS has clearly provided evidences of a powerful approach to assessing the role of neural mechanisms in cardiovascular regulation [19], little is known about this maneuver in normotensive and spontaneous hypertensive rats; highlighting the importance of a better understanding of this procedure for translational purposes.

\section{Stimulation of the Baroreflex Evokes Hemodynamic and Immunological Responses}

Lohmeier et al. [20] showed that prolonged activation of baroreflex through CS stimulation produces sustained hypotension in conscious dogs and could reduce AP and heart rate significantly for one week. By using similar procedure, Domingos et al. [21] showed that compared to normotensive rats, the baroreflex activation was more effective to reduce $\mathrm{AP}$, heart rate and heart rate variability in spontaneous hypertensive rat (SHR). Moreover, this study showed that hemodynamic responses in SHR are frequency dependent.

The immune system plays a key role in protecting the body against foreign pathogens via innate and adaptive immune responses. Recently, several studies have shown specific relationships between the nervous system and immune system, mostly through the vagus nerve fibers connecting the brain with the peripheral immune system. The neural inflammation-sensing pathways have shown to detect activating cholinergic anti-inflammatory responses even in the presence of low inflammatory agents in the periphery [22]. Santos-Almeida et al. [23] demonstrated that electrical stimulation of CS prevented lipopolysaccharide (LPS) systemic inflammation in conscious rats by CS baroreceptors and chemoreceptors activation. This data reveal an important participation of both sympathetic and parasympathetic autonomic nervous system in this response.

\section{Conclusion and Perspectives}

In summary, baroreflex stimulation of CS has been shown useful in different types of hypertension and contributes for the understanding physiopathology of resistant hypertension and neural pathways. Additionally, CS electrical stimulation in a wake rat's may offer a promising platform to clarify the mechanisms involved in the responses evoked by recruitment of autonomic nervous system and immune system. Ultimately, knowledge of this therapeutic strategy can aid in minimizing the impacts of hypertension and potentially suppressing inflammatory diseases.

\section{Acknowledgment}

We thank Fernanda Pohl-Guimaraes for assistance.

\section{References}

1. Miao CY, Xie HH, Zhan LS, Su DF (2006) Blood pressure variability is more important than blood pressure level in determination of endorgan damage in rats. J Hypertens 24(6): 1125-1135.

2. Chapleau MW, Hajduczok G, Abboud FM (1988) Mechanisms of resetting of arterial baroreceptors: an overview. Am J Med Sci 295(4): 327-334.

3. Krieger EM, Salgado HC, Michelini LC (1982) Resetting of the baroreceptors. Int Rev Physiol 26: 119-146.

4. Heusser K, Tank J, Luft FC (2005) Baroreflex failure. Hypertension 45: 834-839.

5. Slavin KV (2015) Stimulation of the Peripheral Nervous System: The Neuromodulation Frontier. Karger Medical and Scientific Publishers.

6. Kennedy SH, Giacobbe P (2007) Treatment resistant depression advances in somatic therapies. Ann. Clin. Psychiatry Off. J Am Acad Clin Psychiatr 19: 279-287.

7. Mauskop A (2005) Vagus nerve stimulation relieves chronic refractory migraine and cluster headaches. Cephalalgia Int J Headache 25(2): 79161.

8. De Ferrari GM, Crijns HJGM, Borggrefe M (2011) Chronic vagus nerve stimulation: a new and promising therapeutic approach for chronic heart failure. Eur Heart J 32(7): 847-855.

9. Ikramuddin S, Blackstone RP, Brancatisano A (2014) Effect of reversible intermittent intra-abdominal vagal nerve blockade on morbid obesity: the Recharge randomized clinical trial. JAMA 312(9): 915-922.

10. Pavlov VA, Tracey KJ (2006) Controlling inflammation: the cholinergic anti-inflammatory pathway. Biochem Soc Trans 34(60029: 1037-1040.

11. Calhoun DA, Jones D, Textor S (2008) Resistant hypertension: diagnosis, evaluation, and treatment. A scientific statement from the American Heart Association Professional Education Committee of the Council for High Blood Pressure Research. Circulation 117(25): e510-516.

12. Navaneethan SD, Lohmeier TE, Bisognano JD (2009) Baroreflex stimulation: A novel treatment option for resistant hypertension. J Am Soc Hypertens JASH 3(10): 69-74.

13. Griffith LS, Schwartz SI (1964) Reversal of renal hypertension by electrical stimulation of the carotid sinus nerve. Surgery 61(6): 923931.

14. Neistadt A, Schwartz SI (1967) Effects of electrical stimulation of the carotid sinus nerve in reversal of experimentally induced hypertension. Surgery 61(6): 923-931.

15. Alnima T, de Leeuw PW, Kroon AA (2012) Baroreflex activation therapy for the treatment of drug-resistant hypertension: new developments. Cardiol Res Pract.

16. DiBona GF (2013) Sympathetic nervous system and hypertension. Hypertension 61: 556-560.

17. Doumas M, Faselis C, Kokkinos P, Anyfanti P (2014) Carotid baroreceptor stimulation: a promising approach for the management of resistant hypertension and heart failure. Curr Vasc Pharmacol 12(1): 30-37.

18. Bisognano JD, Bakris G, Nadim MK (2011) Baroreflex activation therapy lowers blood pressure in patients with resistant hypertension: results from the double-blind, randomized, placebo-controlled rheos pivotal trial. J Am Coll Cardiol 58(7): 765-773.

19. Hildebrandt DA, Irwin ED, Cates AW (2014) Regulation of renin secretion and arterial pressure during prolonged baroreflex activation: influence of salt intake. Hypertension 64(3): 604-609.

20. Lohmeier TE, Iliescu R (2015) The baroreflex as a long-term controller of arterial pressure. Physiol Bethesda Md 30(2): 148-158. 
21. Domingos Souza G, Santos-Almeida FM, Luiz Eduardo Silva, Daniel Dias, Carlos Alberto da Silva (2015) Electrical Stimulation of Carotid Sinus in Conscious Normotensive and Spontaneously Hypertensive Rats. FASEB J 29: 648-710.

22. Tracey KJ (2002) The inflammatory reflex. Nature 420: 853-859.
23. Santos Almeida FM, Domingos Souza G, Meschiari CA (2017) Carotid sinus nerve electrical stimulation in conscious rats attenuates systemic inflammation via chemoreceptor activation. Sci Rep 7(1): 6265.

\section{Your next submission with Juniper Publishers} will reach you the below assets

- Quality Editorial service

- Swift Peer Review

- Reprints availability

- E-prints Service

- Manuscript Podcast for convenient understanding

- Global attainment for your research

- Manuscript accessibility in different formats ( Pdf, E-pub, Full Text, Audio)

- Unceasing customer service

Track the below URL for one-step submission https://juniperpublishers.com/online-submission.php 